\title{
PRIMARY STRUCTURE OF A C-HORDEIN GENE FROM BARLEY
}

\author{
by
}

\author{
JOYCELYN ENTWISTLE
}

\author{
Department of Physiology, Carlsberg Laboratory, \\ Gamle Carlsberg Vej 10, DK-2500 Copenhagen Valby \\ and \\ Department of Plant Biology, University of Birmingham, \\ P.O. Box 363, Birmingham B15 2TT, England
}

Keywords: Hordeum vulgare, Horl locus, prolamin, silent gene, storage proteins

The nucleotide sequence of a 2065 base pair HindIII fragment, containing a gene ( $\lambda$ hor $1-14)$ belonging to the Horl locus in barley, has been determined. The fragment consists of $1044 \mathrm{bp}$ of coding region interrupted by an amber codon at base 481 , a 5 ' non-coding region of 428 bp and a 3' non-coding region with $593 \mathrm{bp}$. The deduced amino acid sequence of the mature protein ( 327 amino acids) is characterized by an octapeptide motif PQQPFPQQ which is repeated throughout the peptide chain between a unique 12 amino acid long $\mathrm{NH}_{2}$-terminal and an equally unique 10 amino acid long $\mathrm{COOH}$-terminal end. The proline + glutamine content is $62 \%$ and the next three most abundant amino acids are leucine $(9 \%)$, phenylalanine $(8 \%)$ and isoleucine (3\%). In the 5 ' non-coding region there is a TATA box at $-98 \mathrm{bp}$ from the start methionine. The $3^{\prime}$ non-coding region has a polyadenylation signal $76 \mathrm{bp}$ downstream from the TAA stop codon. The deduced amino acid sequences of the $\mathrm{NH}_{2}$ - and $\mathrm{COOH}$-terminals of $\lambda$ hor 1-14 are very similar but not identical to those known from the Edman degradation and carboxypeptidase $\mathrm{Y}$ analysis of $C$-hordein polypeptides. The 3 ' coding and non-coding region of $\lambda$ hor $1-14$ is closely similar but different in detail to the known C-hordein cDNA clones. One polyadenylation signal is found in $\lambda$ hor $1-14$ whereas two are present in each of the three known C-hordein cDNAs. These differences and the amber codon interrupting the open reading frame indicate that this gene is silent.

\section{INTRODUCTION}

The major seed storage proteins of barley are the alcohol-soluble prolamins, usually termed hordein. The four main groups of hordein, namely the B-, C-, D- and $\gamma$-hordeins, account for approximately $50 \%$ of the total protein in the mature grain. The $\mathrm{B}$ - and $\mathrm{C}$-hordeins are the two major groups and together form $95 \%$ of the total hordein fraction. The structural genes encoding the B-, C- and D-hordein polypeptides are located in separate complex loci on chromosome 5 , designated Hor-2, Hor-1 and Hor-3, respectively $(3,24,44,47)$. SDS-PAGE analyses indicate that $\mathrm{C}$-hordein can be separated into 5 polypeptide groups, C1-C5, with an apparent molecular weight range of $45-80 \mathrm{kD}$. Two-dimensional analyses using IEF and SDS-PAGE resolve the 5 classes into at least 10 component polypeptides thus demonstrating charge polymorphism in each size class $(22,27)$. Southern blot analysis of barley DNA indicates that the Hor-1 gene family is comprised of 3-8 members (39).

Abbreviations: $b p=$ base pair; $I E F=$ iso-electric focusing; $k b p=$ kilo base pair; $k D=$ kilodalton; SDS-PAGE = sodium dodecyl sulphate polyacrylamide gel electrophoresis. 
Edman degradation of C-hordein polypeptides indicates some polymorphism in the amino-terminal end of the polypeptide $(42,45$, 46). Carboxypeptidase $Y$ digestion and the deduced amino acid sequences of partial Chordein cDNA clones indicate that $\mathrm{C}$-hordein polypeptides have conserved carboxy-terminals (17, 39, 41). Chymotryptic peptide sequences and the deduced amino acid sequences of partial cDNA clones indicate that $\mathrm{C}$-hordein polypeptides are made up of a repeating octapeptide motif, PQQPFPQQ $(17,39,50)$ encoded by a 24 nucleotide repeat having a consensus of $\mathrm{CCA}$ CAA CAA CCA TTC CCC CAG CAA.

Hordein polypeptides are synthesized on the endoplasmic reticulum of the endosperm cells and are deposited in protein bodies from 10-30 days after fertilization $(5,6,7,10,11)$. C-hordein polypeptide synthesis is preferentially enhanced when increasing nitrogen fertilization is applied to the developing endosperm (18), indicating a differential regulation of the hordein gene families.

Recently two different genes encoding Bhordein polypeptides and one encoding a $\gamma$ hordein polypeptide have been isolated and sequenced $(8,12,15)$. These analyses have provided information about the primary structure of different hordein polypeptides as well as possible 5' upstream regulatory sequences. As the next step towards understanding the organization and tissue-specific expression of different members of the hordein gene families, a Chordein gene has been isolated and sequenced.

\section{MATERIALS AND METHODS}

\subsection{Chemicals}

Restriction endonucleases, T4 DNA ligase, DNA polymerase I (Klenow fragment) and the M13 universal primer were purchased from Boehringer Mannheim (FRG). $\alpha^{32} \mathrm{P}$ dATP was from New England Nuclear (USA). The Sequenase $^{\mathrm{TM}}$ kit was from the United States Biochemical Company (USA). Nitrocellulose filters were from Schleicher and Schuell (FRG).

\subsection{Construction and screening of a partial HindIII genomic library}

Barley DNA was isolated from immature endosperms of Hordeum vulgare L. cv. Bomi according to the method of Hopp et al. (23). The DNA was partially digested with HindIII restriction enzyme and ligated into bacteriophage $\lambda$ L47.1 DNA (29) and in vitro packaged (21) and plated using E. coli $\mathrm{BJ}^{2} 183 \mathrm{rec} \mathrm{BC}^{-}$strain as host (48). The yield of recombinant phage, determined by dilution plating onto a P2 host, was estimated to be $1.8 \times 10^{6}$. The library was screened using a nick-translated C-hordein cDNA, pc hor 1-3, as a probe (39). Hybridizing clones were plaque purified and phage DNA was prepared (30).

\subsection{Nucleotide sequencing}

A $2 \mathrm{~kb}$ HindIII fragment from $\lambda$ hor $1-14$ was subcloned into pBR328 (13) using E. coli $\mathrm{HB} 101$ as host. Large scale preparation of plasmid pBR328 was made according to the method of BIRNBOIM and DOLY (2) and purified by banding in a caesium chloride gradient. Restriction fragments generated from these subclones were separated by agarose gel electrophoresis and inserted into the bacteriophage vectors M13mp18 and mp19 (33) using E. coli JM101 as host cells. Sequencing was carried out by the dideoxy chain termination method of SANGER (40), using E. coli polymerase I (Klenow fragment) or modified T7 bacteriophage DNA polymerase, as supplied in the Sequenase ${ }^{\mathrm{TM}}$ kit. The universal M13 primer was mainly used, except for 3 cases, where specific 15 mer oligonucleotides were synthesized on an applied Biosystem 380A DNA synthesizer using the phosphoramadite tri-ester method. The sequence data were assembled and analysed on an IBM computer equipped with the Beckman micro-genie programme.

\section{RESULTS}

Screening of $1.8 \times 10^{6}$ recombinant phages resulted in the isolation of 80 clones containing sequences related to the $\mathrm{C}$-hordein cDNA probe (39). HindIII restriction enzyme and Southern blotting analyses identified three size classes of hybridizing fragments of $1.9,2.0$ and $4.0 \mathrm{kbp}$ in the 80 clones. The same three size classes of HindIII fragments can be identified when total 
(a)

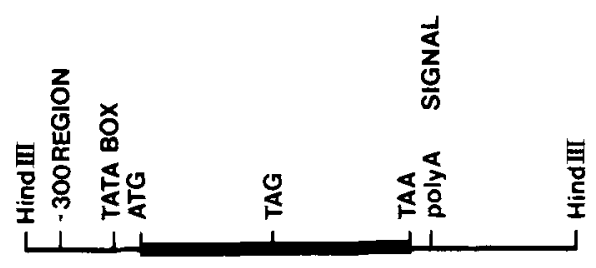

(b)
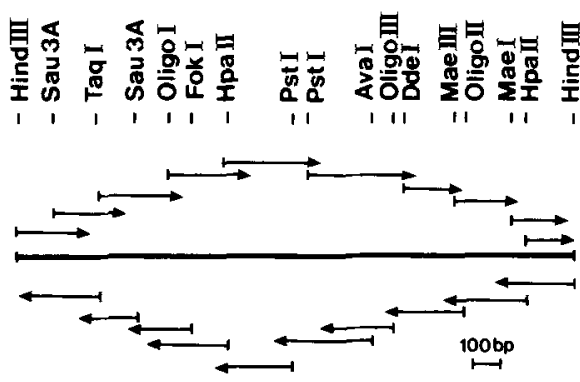

Figure 1. (a) Restriction map of the 2065 base pair HindIII fragment containing the $\mathrm{C}$-hordein gene $\lambda$ hor 1-14. The shaded area indicates the coding region. ATG = start methionine, TAG and TAA = stop codons. (b) Restriction map and sequencing strategy used to determine the nucleotide sequence of the 2065 base pair HindIIl fragment.

barley DNA is analysed. The $2.0 \mathrm{kbp}$ fragment represents the strongest hybridizing size class (39). One clone, $\lambda$ hor 1-14, was chosen from this size group for further analysis. $\lambda$ hor 1-14 contains 4 HindIII fragments of 7.0,2.0, 1.5 and 0.5 $\mathrm{kbp}$. The $2.0 \mathrm{kbp}$ hybridizing fragment was cloned into $\mathrm{pBR} 328$ and mapped with a variety of restriction enzymes. Figure 1 shows the restriction map of the $2.0 \mathrm{kbp}$ fragment of $\lambda$ horl-14 and the strategy used for the nucleotide sequence determination.

\subsection{The deduced amino acid sequence}

The nucleotide sequence and the deduced amino acid sequence of the coding region of $\lambda$ hor 1-14 is shown in Figure 2. The open reading frame of the coding region is composed of 327 amino acids interrupted by an amber codon at base 481 . The recognition of the in-frame amber codon will produce a truncated polypeptide of only 140 amino acids. The sequence R Q L N P $S$ begins at residue 21 and is identical to the $\mathrm{N}$-terminal sequences determined by Edman degradation of isolated $\mathrm{C}$-hordein polypeptides (42). The preceding 20 amino acids are likely to be a signal peptide which is cleaved after the alanine residue. The amino acid sequence of residues 1-20 are highly hydrophobic and there is a charged lysine residue next to the initiation methionine, both of which are characteristics of signal peptides (20). The occurrence of a signal peptide is also consistent with the observation that $\mathrm{C}$-hordein polypeptides are synthesized as larger sized precursors $(7,32)$. The first 25 amino acid residues of the deduced $\mathrm{NH}_{2}$-terminus of גhor 1-14 are highly homologous with those found in C-hordein polypeptides. However, $\lambda$ hor $1-14$ contains two amino acid changes and an insert of six amino acids when compared to the $\mathrm{NH}_{2}$-terminal sequence of a $\mathrm{C}_{2}$-hordein polypeptide:

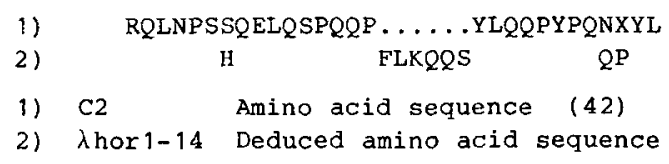

The main body of the deduced amino acid sequence is characterized by a repeating octapeptide with the basic structure of PQQPFPQQ (cf. Figure 3). The same octapeptide repeat motif is found in the deduced amino acid sequences of two partial cDNA clones, Figure 4 $(17,39)$. While the deduced amino acid sequence of the $\lambda$ hor $1-14$ clone and the cDNA clones pc horl-3 (39) and pc P387 (17) are similar polymorphisms in the form of insertions, deletions and amino acid substitutions are present.

In the longer reading frame the repeat motif does not extend to the $\mathrm{COOH}$-terminus as the last 10 amino acids are unique. The deduced $\mathrm{COOH}$-terminal region of $\lambda$ hor $1-14$ is different from those found by carboxypeptidase $\mathrm{Y}$ analysis of C-hordein polypeptides or by deducing the amino acid sequences of three $C$-hordein CDNA clones. The most frequently occurring amino acids are glutamine (122 residues) and proline ( 95 residues) which together account for $62 \%$ of the total. The next 3 most abundant amino acids 
J. ENTWISTLE: C-hordein gene

$-421$

AAGCTTAC

$\begin{array}{llllll}-410 & -400 & -390 & -380 & -370 & -361\end{array}$

AAACTTAGT CCCACT CAGAT ATGCCTAT CTGGATATGACT ACAT AAAGTAGAGCATCACA

$$
\begin{array}{llllll}
-350 & -340 & -330 & -320 & -310 & -301
\end{array}
$$

AACT AAATTCCAAAAAGAGGCAAGACCTAGAT TAT GTGTGTAGTGT AAAGT AAAAAAAAT

$-290 \quad-280 \quad-270 \quad-260 \stackrel{-250}{\longrightarrow}-241$

GACTCATCATTCATTATGGATCATGACTTACAACCAGATGATATTTGCAAAAAAAACAAC

$$
\begin{array}{llllll}
-230 & -220 & -210 & -200 & -190 & -181
\end{array}
$$

TATGTTGAGCAAT CCAAAAT CACACAAGTAAAGT AGTACCACCAAACACAACATACCAAA

$$
\begin{array}{llllll}
-170 & -160 & -150 & -140 & -130 & -121
\end{array}
$$

\begin{tabular}{|c|c|c|c|c|c|}
\hline-110 & -100 & -90 & -80 & -70 & -61 \\
\hline CCATACCATGA? & ITAAA & & rGGT & & $A A$ \\
\hline-50 & -40 & -30 & -20 & -10 & -1 \\
\hline
\end{tabular}

CGATT AGTT GGAT AAT CTTAGGAGT ACTT TTTCGAAAAGCAAGGCAAGGATGGAATT AAA

TTTACACACCAAGATCAGAAACATCTAT TCCAAGCAAGCAATAGTAACCAAAAATCCAAC

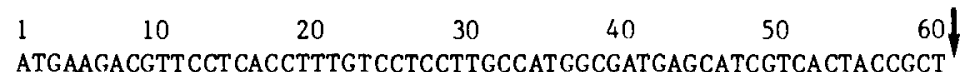
Met Lys ThrPhe LeuThrPheVa lLeuLeuAlaMet AlaMet Ser I leValThrThrAla

$\begin{array}{lllll}70 & 80 & 90 & 100 & 110\end{array}$

AGGCAGCTAAACCCTAGCCACCAAGAGTTGCAATCACCACAACAACCATTTCT GAAACAA ArgGlnLeuAsnP roSerH1sGInGluLeuGlnSerProG InG InP roPheLeuLy sGin

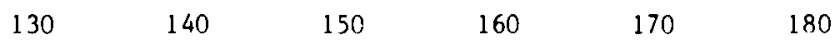

CAATCATAT CTGCAACAACCATATCCACAACAACCATATCTACCGCAGCAACCATTCCCC

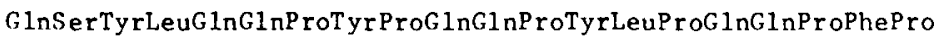

$190 \quad 200 \quad 210 \quad 220 \quad 230 \quad 240$ ACACCCCAACAATT TTTCCCCTAT CT ACCACAGCAAACATTT CCCCCATCCCAACAACCA ThrP roG InGlnPhePheProTyrLeuProGlnGInThrPheProProSerGingInPro

$250 \quad 260 \quad 270 \quad 280 \quad 300$

AACCCCCTACAACCACAACAACCATTCCCCCT GCAACCCCAACCACCACAACAACCTTTT AsnProLeuGinProG InGInProPheProLeuGlnProGlnProProG $1 n G 1$ ProPhe

$\begin{array}{lllll}310 & 320 & 330 & 340 & 350\end{array}$
CCTCAGCCCCAACAACCAAATCCCCAGCAACCACAACAACCTTTCCCCCGGCAACCACAA ProGlnProG InG1nP roAsnProGlnG InProG InG1nProPheProArgG1nProGin

$\begin{array}{lllll}370 & 380 & 390 & 400 & 410\end{array}$

CAAATAGTACCCCAGCAACCACAACAACCAT TCCCTCAGCAACCACAACAACCTTTTCCT G1nIleValProGinG1nProGlnGlnProPheProG1nGlnProGlng lnProPhePro
430
440
450
460
470
480

CACCCCCAACAACCATTCT CTTGGCAACCACAACAACCATTTCTCCAGCCCCTACAACTA GInProG InG InProPheSerT rpG InP roG InG InP roPhe LeuG InProLeuG InLeu

$490 \quad 500 \quad 510 \quad 520 \quad 530 \quad 540$

TAGCCCCTGCAAGCACAACAACCATTCCCCTTGCAACCT CAACTACCATTTCCGCAACCC EndProLeuGInAlaGlnGlnProPheProLeuGInProGl nLeuProPheProGinP ro

Figure 2. Nucleotide sequence and deduced amino acid sequence of the gene $\lambda$ hor 1-14. Horizontal arrows indicate the '-300' region, direct and inverted repeats. The vertical arrow after position 60 indicates the most likely cleavage point of the signal peptide. The TATA box (TATAAATA), stop codons (TAG and TAA) and the polyadenylation signal are boxed. 
$550 \quad 560 \quad 570 \quad 580 \quad 590 \quad 60$

CAACAACCAATTGGACAGCAACCAAAACAACCACTCCTGCAGCAACCACAACAAACAATT GInGlnProIleGlyGlnGlnProLysGInProLeuLeuGlnGlnProGlnGlnThrIle

$\begin{array}{lllll}610 & 620 & 630 & 640 & 650\end{array}$
CCCCAGCAACCACAACAACCATT CCCCCTGCAGCCGCAACAACCATT CCCCCAACAACCA ProG InG InProG InG InP roPheP roLeuG InProGlnG InProPheProGInGinPro

$\begin{array}{lllll}670 & 680 & 690 & 700 & 710\end{array}$ CAACAACCACTT CCCCAACAACCCCAACAAAT AATTTCCCAGCAACCCCAACAACCATTC GlnGlnProLeuProGlnGlnProGlnGlnIle IleSerGlnG InProGlnG InProPhe

$\begin{array}{lllll}730 & 740 & 750 & 760 & 770\end{array}$ CCTCTACAACCTCAACAACCATT CCCCCAACCCCAACCATTCCCCCAGGAGCAACCCCAA ProLeuGlnProGInG InProPheProGlnProGlnProPheProGlnG IuGlnProGin

$\begin{array}{lllll}790 & 800 & 810 & 820 & 830\end{array}$

CAAGCATT TCCCCTACAACCGCAACAACCATTCCCCGAGGAATCAGAACAAATAATT ACC GlnAlaPheP roLeuGlnProGInGlnProPheProGluGluSerGluGlnIleI leThr

$\begin{array}{llllll}850 & 860 & 870 & 880 & 890 & 900\end{array}$
CAACAACCATT CCCTCTACAACCACAACAACTGTTCCCCCAGCAACCACAACAACCACTT GInGlnProPheProLeuGlnP roG InG InLeuPheP roG InG InProG InG InProleu

$910 \quad 920 \quad 930 \quad 940 \quad 950 \quad 960$ CCCCAGCCCCAACAACCATT CCGCCAACTACCAAAAT ATATAATTCCCCAGCAACCT CAA ProGlnProGlnGlnProPheArgGlnLeuProLysT yrIle I le ProGlnGlnProGln

$\begin{array}{llllll}970 & 980 & 990 & 1000 & 1010 & 1020\end{array}$ CAACCATT CCTTCTGCAACCACACCAACCTCAGCAACCTTATGCACAACAAGACAT CTGG G1nProPheLeuLeuGlnProHisGlnProG1nG1nProTy rAlaGlnG1nAs pI leT rp

$\begin{array}{llllll}1030 & 1040 & 1050 & 1060 & 1070 & 1080\end{array}$
AGTGATATAGCCCTCTTGGGCTAATGAAGCGAAAAGTT GTAATACT AGATGGGTGTATCA SerAspIleAlaLeuLeuGly End

$1090 \quad 1100 \quad 1110 \quad 1120 \quad 1130 \quad 1140$ TCGTTGT TT AGTCAGTGAGTGTTCCAGTGTATTGATCATGAATAAAGTGAT GTGCACCAT
$\begin{array}{llllll}1150 & 1160 & 1170 & 1180 & 1190 & 1200\end{array}$

CATGTGTAAT CCCGACCTATACTAGTT CAAGCATGAGAAAAGGACAAGAAGTTGT CACAA

$\begin{array}{llllll}1210 & 1220 & 1230 & 1240 & 1250 & 1260\end{array}$ GGACAATGATGGTAATTTTTACCATTCATGCCATATTT AGATTTTTTTCCCTCAACTAT A $\begin{array}{llllll}1270 & 1280 & 1290 & 1300 & 1310 & 1320\end{array}$ ATTTGAGTCATATGCATTATCTACCTATTTATGAAGTGAAGCCCTATGAGCCAAACATTA $\begin{array}{llllll}1330 & 1340 & 1350 & 1360 & 1370 & 1380\end{array}$ TTAATGGTTGTCAAACTTGGTTTGAATTTGATTATTAGCAAATAAGGAGTATGAAGTAAT

$\begin{array}{llllll}1390 & 1400 & 1410 & 1420 & 1430 & 1440\end{array}$
TGCAAATTAT CTCTTCGGTGGCTAGT CGTATGAACT GTGTGACT TGCAAGTTATTCAAAT $\begin{array}{lllll}1450 & 1460 & 1470 & 1480 & 1490\end{array}$ GGTTCCTTTAATGGACCGGTTGCTCATGTTAGAAAATATGGGCTTGCGCCGTATTGATTT

$\begin{array}{llllll}1510 & 1520 & 1530 & 1540 & 1550 & 1560\end{array}$ CTTGCAAATGGACAATATGAAGGGTAGATTGAATTTATTCCTTCTATTTCT CCTCCACAT

$\begin{array}{llllll}1570 & 1580 & 1590 & 1600 & 1610 & 1620\end{array}$
GT ATT ACGAGTTACTTAGAGAAGTTCCACCAGACTGATATGGT CCACTTGGT AT AGCTAC

1630

CCAATGGTCGGAAGCTT 


\section{J. ENTwISTLE: C-hordein gene}

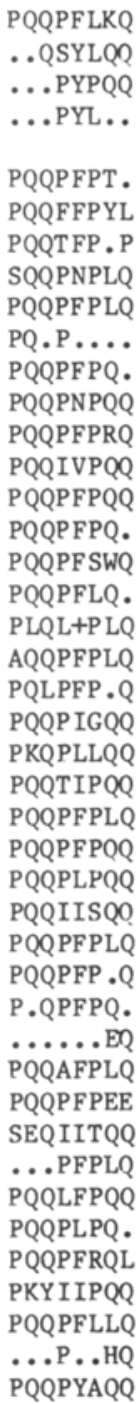

DIWSDIALLG

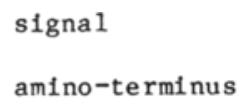

Figure 3. Repetitive motif of 24 nucleotides in the coding region of $\lambda$ hor $1-14$ and the deduced octapeptides. Shading highlights the proline and glutamine codons. The amino- and carboxy-terminal regions are unique. The TAG stop codon interrupting the open-reading frame is boxed. 


\begin{tabular}{|c|c|c|}
\hline hor $1-14$ & pc P 387 & pc hor $1-3$ \\
\hline QQPFP.Q & PQQSYPVQ & \\
\hline .QPFPQ. & PQQPFPQ. & \\
\hline$\ldots . . \mathrm{EQ}$ & PQ.PVPQQ & \\
\hline QQAFPLQ & PQQASPLQ & \\
\hline QQPFPEE & PQQPFPQG & $\ldots . \mathrm{FPQ}$ \\
\hline EQIITQQ & SEQII ... & PQQPFPQQ \\
\hline ..PFPLQ & PQQPFPLQ & PQQPFPLQ \\
\hline QQLFPQQ & PQ.PFPQQ & PQQPFPQQ \\
\hline QQPLPQ. & PQQPLPQ. & PQQPFPQ. \\
\hline QQPFRQL & PQQPFRQQ & PQQPFRQQ \\
\hline KYIIPQQ & AEL I IPQQ & AEL I IPQQ \\
\hline QQPFLLQ & PQQPLPLQ & PQQPFPLQ \\
\hline
\end{tabular}

Figure 4. A comparison of the deduced amino acid sequence from $\lambda$ hor 1-14 and the two $C$-hordein cDNA clones, pc P387 and pc hor 1-3. The alignment was made amino terminal to the leucine and glutamine residues encoded by the Pst 1 site, CTGCAG, in the two cDNA clones.

are leucine $(8.9 \%)$, phenylalanine $(7.8 \%)$ and isoleucine (3.4\%). In agreement with the amino acid analysis of mature $\mathrm{C}$-hordein polypeptides there are no cysteine residues. There is a good agreement between the amino acid composition of the deduced sequence of $\lambda$ hor 1-14 and that of purified C2-hordein polypeptides, with the exception of lysine. $\lambda$ hor 1-14 has an overall content of $1.1 \%$ mole of lysine whereas the $\mathrm{C} 2$ polypeptide was determined to have a lysine content of only $0.2 \%$ (41). There are 4 lysine residues in $\lambda$ hor $1-14$, one being in the signal peptide. The codon usage is not biased except in the case of glutamine in which CAA is used 103 times whereas $\mathrm{CAG}$ is only used 19 times.

\subsection{Nucleotide analysis of the coding region}

With the exception of the regions encoding the signal peptide, the first 12 amino acids of the $\mathrm{N}$-terminus and the last 10 amino acids of the C-terminus a tandemly repeated nucleotide sequence dominates the $\lambda$ hor $1-14$ gene (Figure 3 ) in the longer open reading frame. The 24 nucleotide motif of the repeating sequence has the following consensus:

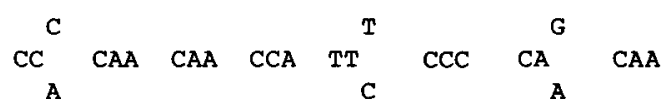

Frequently, the repeats are degenerate as a result of nucleotide substitutions, deletions and insertions as shown in Figure 3. The TAG stop codon interrupting the open-reading frame, is located in a 5 th codon position of the respective element and, therefore, probably originated by two point mutations from a phenylalanine codon (TTT).

An alignment of $\lambda$ hor $1-14$ with the cDNA

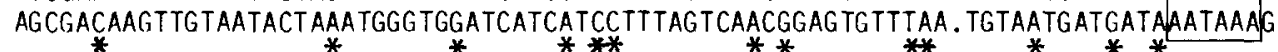

Figure 5. Alignment of $\lambda$ hor 1-14 (A) and the C-hordein cDNA clone, pc hor 1-3 (B) in the carboxy-terminal and 3' non-coding regions. Gaps introduced for maximum alignment are indicated by dots. Asterisks indicate nucleotide differences between the two sequences. Stop codons are underligned and polyadenylation signals are boxed. 
clone pc hor1-3 (39) shows close similarity but also microvariation in the form of insertions, deletions and point mutations (Figure 5). The Pst 1 site, CTGCAG, present in the three previously studied cDNA clones $(17,39)$ is not found in the gene $\lambda$ hor $1-14$, because the glutamine codon CAA is used instead of CAG, in the position where a Pstl site would be expected. The stop codon TAG is used in the cDNA clones whereas the genomic clone has a TAA stop codon 12 nucleotides further downstream. There is one polyadenylation signal in the 3 ' non-coding region of $\lambda$ hor1-14 whereas the C-hordein cDNA clones contain two polyadenylation signals. The alignment of the $\lambda$ hor $1-14$ and pc hor $1-3$ sequences reveals a three nucleotide deletion in $\lambda$ hor 1-14 whereby the second polyadenylation signal has been eliminated (Figure 5).

\subsection{The 5 ' non-coding region of $\lambda$ hor $1-14$}

Coordinate induction of genes by cis interaction with a common regulatory molecule requires that homologous sequences are present in the vicinity of the genes. Shared sequence elements have been found in genes that are functionally related and that are induced in concert (14). Sequences in the 5' non-coding region are thus expected to control tissue specific and temporal gene expression of hordein genes. Some of the regulatory sequences may be specific for a Hor locus while others may be shared by members of different Hor loci. For a comparative analysis the 5' non-coding region of the $C$-hordein gene $\lambda$ hor $1-14$ was aligned with that of the B-hordein gene $\lambda$ hor2-4 (8), a $\gamma$ hordein gene (12) and the $\alpha / \beta$-gliadin gene pW8233 (37) from wheat. Although the $\alpha / \beta$ gliadins are similar to $B$-hordeins in terms of size and amino acid composition they are considered to represent two of the most divergent groups of S-rich prolamins (27) and it was thus considered of interest to include the wheat gene in this comparison. The alignment of the four sequences was made partly by computer and partly by eye, introducing gaps where appropriate. The most highly conserved regions of the four genes are shown in Figure 6.

Region $\mathrm{A}$ is the '-300 region' which has been identified in most prolamin genes and is thought to act as a transcriptional enhancer. In $\lambda$ hor 1-14 the ' -300 ' region is located between -294 and -324 base pairs from the start methionine (cf. Figure 2). This sequence contains a portion which is homologous to the core sequence of the SV40 enhancer (53), namely TGTAAAGT which is seen in all four genes. A closely related 8 base pair sequence with this motif in the form GTAAAGTA is present at position -206, in the $\lambda$ hor $1-14$ gene. The 8 adenine nucleotides immediately downstream of the enhancer sequence at -310 in $\lambda$ hor $1-14$ are replaced in the Band $\gamma$-hordeins and the $\alpha / \beta$-gliadin gene by the nucleotide sequence GAATAAGA ${ }_{G}$. Regions $B$ and $C$ may represent CAAT boxes and region $\mathrm{D}$ is a typical TATA box which may act as a transcriptional promotor $(25,43)$. The TATA box in thor $1-14$ is located at -98 base pairs from the start methionine. It is noteworthy that there is an 8 base pair inverted repeat bracketing the TATA box (Figure 2). Analysis of the nopaline synthase promoter has shown that maximum efficiency of transcription requires the interaction between the binding capacities of both the CAAT and TATA box regions (43). Nuclease $S 1$ protection of messenger RNA start points with probes from the $\alpha / \beta$-gliadin gene pW8233 (38) and the $\gamma$-hordein gene (12) has identified the 5' end of region $\mathrm{E}$, indicated by an arrow in Figure 6 , as the transcriptional start of the two genes. On the basis of sequence similarity the transcriptional starting points for the $\mathrm{B}$-hordein and $\mathrm{C}$-hordein are also considered to be located at the 5 ' end of region $\mathrm{E}$. The numbers of nucleotides separating the conserved regions of the $C$-hordein, $\gamma$-hordein and $\alpha / \beta$-gliadin genes are very similar. However, the $\mathrm{B}$-hordein gene has three times as many nucleotides spacing region $\mathrm{B}$ from $\mathrm{C}$ and only half as many nucleotides between regions $\mathrm{C}$ and $\mathrm{D}$ as compared to the other three genes.

The significance of the similarities and differences between the 5' non-coding regions among the four genes, in terms of tissue specific and temporal expression, remains to be determined. It has recently been shown that 549 bp of 5 ' non-coding region of a $\mathrm{B} 1$ hordein gene are sufficient to direct the tissue specific and temporal expression of the chloramphenicol acetyl transferase gene in tobacco (31). However, func- 
$\begin{array}{lllll}\text { A } & \text { B } & \text { C } & \text { D } & \text { E }\end{array}$

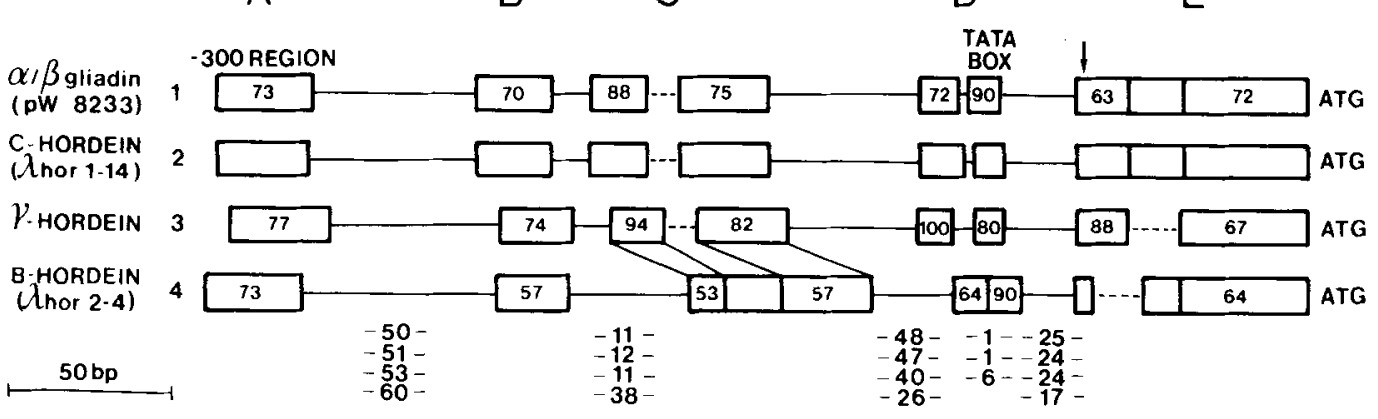

1 TTTGAG CTGTAAAGTGAATAAGATGAGT CA

A 2 TGTGTAGTGTAAAGTAAAAAAAATGACTCA

3 TGTGAGATGTAAAGTGAaTAaGATGAGT CA

4 TGTGACATGTAAAGTGAATAAGGTGAGT CA

AACTTT TATGACCAGT CCAAGAA

B AACTATGTTGAG CAAT CCAAAAT

AACTTTGATG ATGTGT CCAAAAT

AACTTTGATTA....T.C. .AAT

GTAGTG CCACCAAACAG ......... AACATA CCAAATGATGATTTTTAGAAG C

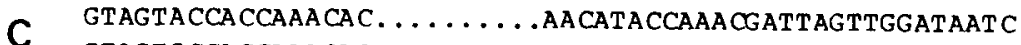

GTAGT GCACCAAACAC........ AAA CATT CCAAATGAT CAGTT CGATAAG C

.T . GT . ... . CCAAAAAT CCATT TG CAAAAG CAT CCAAAC. A . CAATTGTTAAAG C

T. CCATGG.CA CTATAAATAG

D A.cCATGa.TA CTATAAATAa

A. CCATGA.TA CTATAAAGAG

AGCC.TGGCTA CTATAAATAG

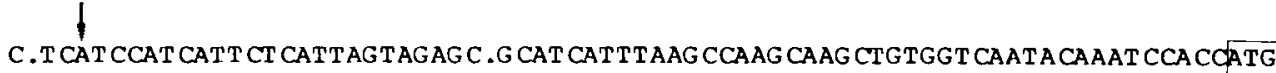

$\mathbf{E}$

CAT CAT CCAAA CT TT A CA CA CCAAGAT CAGAAA CAT CT ATT CCAAG CAAG CAAT AGTAA CCAAAAAT CCAA CATG

CAT CAT CCAT CCTTTA . . . . . . . . . CAT .TACT . AAGAAAGGT T T AG CTAACA CAAAT CCA CCATG

CTACA .............. CAAG . CA CAAG CAT CAAAA CCAAGAAACAC. TAGTTAA CA CCAAT CCA CIATG

Figure 6. Diagram showing the conserved sequences in the 5' non-coding regions of a B-hordein gene ( $\lambda$ hor $2-4)$, a $\gamma$-hordein gene, an $\alpha / \beta$-gliadin gene (pW8233) and in the $C$-hordein gene $\lambda$ hor $1-14$. The alignment was made partly by computer and partly manually. The percentage of homology between the conserved regions of the three genes with the corresponding regions in the $\mathrm{C}$-hordein gene are indicated by the figures in the boxed areas. Dotted lines indicate where gaps have been introduced to give maximum sequence alignment. The number of nucleotides separating the conserved regions in the 4 genes are indicated.

tional mapping of the 5 ' non-coding region will be necessary to demonstrate the precise role of the highly conserved regions.

\section{DISCUSSION}

$\lambda$ hor1-14 is the first C-hordein gene to be isolated and sequenced. The gene presented in this paper is identified as a member of the Hor-1 locus by the following criteria:

The gene encodes a polypeptide with a deduced amino acid sequence which has about $70 \%$ sequence identity to the $\mathrm{NH}_{2}$-terminal sequences of $\mathrm{C}$-hordein polypeptides as determined by Edman degradation. The octapeptide repeat motif, apparent in the deduced amino acid sequence of $\lambda$ hor 1-14 has been determined 
in chymotryptic peptides of C-hordein as well as in the deduced amino acid sequences of $\mathrm{C}$ hordein cDNA clones. Finally, $\lambda$ hor 1-14 has a 5' non-coding region with sequences which are highly conserved in genes encoding other prolamin storage proteins.

The coding region of 1044 base pairs is interrupted by a TAG stop codon at base 481 . If the amber codon is suppressed then the gene encodes a mature polypeptide of 327 amino acids, however, if the stop codon is functional then a mature truncated polypeptide of only 140 amino acids is translatable. The in-frame amber codon located at base 481 in the open reading frame is either due to a double mutation in a phenylalanine codon TTT or the result of a substantial insertion or deletion of nucleotides in this area. Since the motif has not been disrupted the latter is unlikely. Although introns have not been identified in prolamin genes the amber codon and surrounding area may be a small intron. However, typical intron/exon splice sites have not been identified in $\lambda$ hor 1-14 (9). Whether the gene, $\lambda$ hor $1-14$ is expressed in the developing endosperm or silent remains to be determined.

In frame stop codons interrupting open reading frames of several other animal and plant genes belonging to multi-gene families have been reported. Examples of these are genes of the human $\alpha / \beta$-globin gene families $(35,36)$, human leukocyte interferon genes $(51,54)$, a $\gamma$-gliadin gene from wheat (38), a high molecular weight glutenin gene from wheat (16), a legumin gene from pea (4) and three zein genes from maize $(28,49,52)$. Two of the zein genes have one stop codon and one gene has four internal stop codons in an otherwise normal coding region.

Non expressed genes reported in the literature show either an absence of regulatory upstream and downstream sequences or the presence of mutations/deletions in these sequences. The '-300 region' of a silent HMW glutenin is only partially present (16) and mutated polyadenylation signals have been reported in silent zein genes (49).

A comparison between the upstream regions of two $\gamma$-gliadin genes, one with two premature stop codons and one without a premature stop codon, showed no appreciable differences in the 5 ' flanking regions. However, this does not preclude the possibility of differences between the two genes further upstream.

In some cases non-typical intervening sequences in the coding region or the occurrence of poly A tracts in the 3 ' downstream region caused by the incorporation of reverse transcribed mRNA has resulted in pseudogenes which show almost no similarity to their gene family counterparts $(35,54)$. In the case of $\lambda$ hor 1-14 the amber codon interrupts an otherwise normal coding region which does not contain any intervening or atypical sequences. The 5 ' non-coding region is highly similar to those of the genes encoding B- and $\gamma$-hordein polypeptides.

It is assumed that genes containing stop codons interrupting the coding regions are not expressed. Transcripts containing in-frame stop codons have been reported for a human leukocyte interferon gene, a class I major histocompatibility gene from rat and an SSU of ribulose biphosphate carboxylase gene from tobacco $(19$, 26, 34). Transcript levels, however, are low and subsequent translation into a protein has not been demonstrated. Exceptions may be some zein genes which produce truncated polypeptides $(49,52)$.

Suppression of an amber codon in the tobacco mosaic virus by a cytoplasmic tRNA ${ }^{\text {tyr }}$ isolated from lupin seeds produces a read through protein of $183 \mathrm{kD}$ in Xenopus oocytes (1). Although the expression of $\lambda$ hor 1-14 is open to question, the coding sequence is assumed to be similar to that of expressed C-hordein genes. This is substantiated by the high degree of homology between the coding region and 3' non-coding region of $\lambda$ horl-14 and the $\mathrm{C}$ hordein cDNA clones which have been analysed.

\section{ACKNOWLEDGEMENTS}

This work was supported by the Biotechnological Action Programme of the Commission of the European Communities with contract no. BAP-0091-DK to Professor D. von WETTSTEIN. The author is very grateful for advice and guidance given by Dr. ANDERS BRANDT and Dr. H. JOHN NEWBURY during the course of this 
work. Nina RaSMUSSEN and LISE TRILlot are thanked for their help with the preparation of the figures and the manuscript.

\section{REFERENCES}

1. BarciszewSki, J., M. BarciszeWSKA, B. SUTER \& E. KUBLI: Plant tRNA suppressors: in vivo readthrough properties and nucleotide sequence of yellow lupin seeds tRNA ${ }^{\text {Tyr. }}$. Plant Science 40, 193-196 (1985)

2. BIRNBOIM, H.C. \& J. Doly: A rapid alkaline extraction procedure for screening recombinant plasmid DNA. Nucl. Acids Res. 7, 1513-1517 (1979)

3. BLAKE, T.K., S.E. UlLRICH \& R.A. NilaN: Mapping of Hor-3 locus encoding $D$ hordein in barley. Theor. Appl. Genet. 53, 367-371 (1982)

4. Bown, D., M. LeVASSEUR, R.R.D. Croy, D. BoulTER \& I A. GATEHOUSE: Sequence of a pseudogene in the legumin gene family of pea. (Pisum sativum L.) Nucl. Acids Res. 13, 4527-4538 (1985)

5. BRANDT, A.: Endosperm protein formation during kernel development of wild type and a high-lysine barley mutant. Cereal Chem. 53, 890-901 (1976)

6. BRANDT, A. \& J. INGVERSEN: In vitro synthesis of barley endosperm proteins on wild type and mutant templates. Carlsberg Res. Commun. 41, 311320 (1976)

7. BRANDT, A. \& J. INGVERSEN: Isolation and translation of hordein messenger RNA from wild type and mutant endosperm in barley. Carlsberg Res. Commun. 43, 451-469 (1978)

8. Brandt,A., A. Montembault, V.Cameron-Mills \& S.K RASMussen: Primary structure of a B1 hordein gene from barley. Carlsberg Res. Commun. 50, 333-345 (1985)

9. BROWN, J.W.S.: A catalogue of splice junction and putative branch point sequences from plant introns. Nucl. Acids Res. 14, 9549-9559 (1986)

10. Cameron-Mills, V. \& J. Ingversen: In vitro synthesis and transport of barley endosperm proteins. Reconstitution of functional rough microsomes from polyribosomes and stripped microsomes. Carlsberg Res. Commun. 43, 471-489 (1978)

11. Cameron-Mills, V. \& D. von Wettstein: Protein body formation in the developing barley endosperm. Carlsberg Res. Commun. 45, 577-594 (1980)

12. Cameron-Mills, V. \& A. Brandt: A $\gamma$-hordein gene. (submitted)

13. Covarrubias, L., L. Cervantes, A. Covarrubias, X. SOBERON, I. VICHIDO, A. BLANCO, Y.M. KUPERSZTOCH-PORTNOY \& F. BOLIVAR: Construction and characterization of new cloning vehicles, $V$. Mobilization and coding properties of pBR322 and several deletion derivatives including $\mathrm{pBR} 327$ and pBR328. Gene 13, 25-35 (1981)

14. Davidson, E.H., H.T. JaCoBs \& R.J. BritTen: Very short repeats and co-ordinate induction of genes. Nature 301, 468-470 (1983)

15. Forde, B.G., A. HeYworth, J. PYwell \& M. KReis: Nucleotide sequence of a $B 1$ hordein gene and the identification of possible upstream regulatory elements in endosperm storage protein genes from barley, wheat and maize. Nucl. Acids Res. 13, 7327-7339 (1985)

16. Forde, J., J.-M. Malpica, N.G. Halford, P.R. SHeWry, O.D. ANDERSON, F.C. GREene \& B.J. MIFLIN: The nucleotide sequence of a $\mathrm{HMW}$ glutenin subunit gene located on chromosome $1 \mathrm{~A}$ of wheat (Triticum aestivum L.). Nucl. Acids Res. 13,68176832 (1985)

17. Forde, B.G., M. KREIS, M.S. Williamson, R.P. Fry, J. Pywel, P.R. SHewry, N. Bunce \& B.J. MifLIN: Short tandem repeats shared by $\mathrm{B}$ - and $\mathrm{C}$-hordein cDNAs suggest a common evolutionary origin for two groups of cereal storage protein genes. EMBO J. 4, 9-15 (1985)

18. GIESE, H. \& H.E. Hopp: Influence of nitrogen nutrition on the amount of hordein, protein $\mathrm{Z}$ and $\beta$-amylase messenger RNA in developing endosperms of barley. Carlsberg Res. Commun. 49, 365-383 (1984)

19. GoEDDEL, D.V., D.W. LeUNG, T.J. DULL, M. Gross, R.M. Lawn, R. McCandliss, P.M. SeeburG, A. UllRich, E. Yelverton \& P.W. GraY: The structure of eight distinct cloned human leukocyte interferon cDNAs. Nature (London) 290, p. 20 (1981)

20. HEIJNE, G. von: On the hydrophic nature of signal sequences. Eur. J. Biochem. 116, 419-422 (1981)

21. HoHN, B. \& K. MurRaY: Packaging recombinant DNA molecules into bacteriophage particles in vitro. Proc. Natl. Acad. Sci. USA 74, 3259-3263 (1977)

22. HOLDER, A.A. \& J. INGVERSEN: Peptide mapping of the major components of in vitro synthesized barley hordein: Evidence for structural homology. Carlsberg Res. Commun. 43, 177-184 (1978)

23. Hopp, H.E., S.K. RasmuSSEn \& A. BRANDT: Organization and transcription of $\mathrm{B} 1$ hordein genes in high lysine mutants of barley. Carlsberg Res. Commun. 48, 201-216 (1983)

24. JENSEN, J., J.H. JøRGENSEN, H.P. JENSEN, H. GIESE \& H. DoLL: Linkage of the hordein loci, Hor 1 and Hor 2 with the powdery mildew resistance loci MI-k and MI-a on barley chromosome 5. Theor. Appl. Genet. 58, 27-31 (1980)

25. JoshI, C.P.: An inspection of the domain between putative TATA box and translation start site in 79 
plant genes. Nucl. Acids Res. 15, 6643-6653(1987)

26. KASTERN, W: Characterization of two class I major histocompatibility rat cDNA clones, one of which contains a premature termination codon. Gene 34, 227-233 (1985)

27. KREIS, M., P.R. SHEWRY, B.G. FORDE, J. FORDE\& B.J. MIFLIN: Structure and evolution of seed storage proteins and their genes, with particular reference to those of wheat, barley and rye. Oxford Surveys of Plant Cell and Molecular Biology 2 (Miflin, B.J. Ed.) Oxford, 253-317 (1985)

28. KRIDL, J.C., J. VieiRa, I. RUBENSTEIN \& J. MESSING: Nucleotide sequence analysis of a zein genomic clone with a short open reading frame. Gene 28 , 113-118 (1984)

29. LOENEN, W.A.M. \& W.J. BRAMMER: A bacteriophage lambda vector for cloning large DNA fragments made with several restriction enzymes. Gene 10, 249-259 (1980)

30. Maniatis, T., E.F. Fritsch \& J. SambrooK: Molecular cloning, a laboratory manual. Cold Spring Harbor Laboratory Press, NY (1982)

31. Marris, C., P. Gallois, J. Copley \& M. KReis: The 5 ' flanking region of a barley $B$ hordein gene controls tissue and developmental specific CAT expression in tobacco plants. Plant Mol. Biol. 10, 359-366 (1988)

32. Mathews, J.A. \& B.J. MifuiN: In vitro synthesis of barley storage proteins. Planta 149, 262-268 (1980)

33. Messing, J. \& J. Vieira: A new pair of M13 vectors for selecting either DNA strand of double-digest restriction fragments. Gene 19, 269-276 (1982)

34. O'Neal, J.K, A.R. Pokalsky, K.L. KiehNe \& C.K. SHEWMAKER: Isolation of tobacco SSU genes: characterization of a transcriptionally active pseudogene. Nucl. Acids Res. 15, 8661-8677 (1987)

35. Proudfoot, N.J.: Pseudogenes. Nature (London) 286, 840-841 (1980)

36. Proudfoot, N.J., A. Gil \& T. Maniatis: The structure of the human Zeta globin gene and a closely linked nearly identical pseudogene. Cell 31, 553563 (1982)

37. Rafalski, J.A., K. Sheets, M. Metzler, D.M. PETERSON, C. HEDGCOTH \& D.G. SOLL: Developmentally regulated plant genes: the nucleotide sequence of a wheat gliadin genomic clone. EMBO J. 3, 1409-1415 (1984)

38. RAFALSKI, J.A: Structure of wheat gamma-gliadin genes. Gene 43, 221-229 (1986)

39. Rasmussen, S.K \& A. BrandT: Nucleotide sequences of cDNA clones for C-hordein polypeptides. Carlsberg Res. Commun. 51, 371-379 (1986)

40. SANGer, F., S. Nicklen \& A.R. Coulson: DNA sequencing with chain-terminating inhibitors.
Proc. Natl. Acad. Sci. USA 74, 5463-5467 (1977)

41. SCHмITT, J.M.: Purification of hordein polypeptides by column chromatography using volatile solvents. Carlsberg Res. Commun. 44, 431-438 (1979)

42. SCHMitT, J.M. \& I. SVEndSEN: Amino acid sequences of hordein polypeptides Carlsberg Res. Commun. 45, 143-148 (1980)

43. Shaw, C.H., G.H. Carter, M.D. Watson \& C.H. SHAW: A functional map of the nopaline synthase promotor. Nucl. Acids Res. 12, $7831-7846$ (1984)

44. Shewry, P.R., A.J. Faulks, R.A. Pickering, I.T. JONES, R.A. FINCH \& B.J. MIFLIN: The genetic analysis of barley storage protein. Heredity 44,383 $389(1980)$

45. Shewry, P.R., J.-C. Autran, C.C. Nimmo, E.J.-L. LEW \& D.D. KASARDA: N-terminal amino acid sequence homology of storage protein components from barley and a diploid wheat. Nature 286 , 520-522 (1980a)

46. SHEWRY, P.R., E.J.-L. LEW \& D.D. KASARDA: Structural homology of storage proteins coded by the Hor 1 locus of barley (Hordeum vulgare L.). Planta 153, 246-253 (1981)

47. Shewry, P.R., R.A. Finch, S. Parmar, J. Franklin \& B.J. MrfLIN: Chromosomal location of Hor3, a new locus governing storage proteins in barley. Heredity 50(2), 179-189 (1983)

48. Souciet, J.-L., J.C. Hubert \& F. Lacroute: Cloning and restriction mapping of the yeast URA 2 gene coding for carbamyl phosphate synthetase aspartate-transcarbamylase complex. Mol. Gen. Genet.186, 385-390 (1982)

49. SPena, A., A. Viotti \& V. Pirotta: A homologous repetitive block structure underlies the heterogeneity of heavy and light chain zein genes. EMBO J. 1, 1589-1594 (1982)

50. TATHAM, A.S., A.F. DRake \& P. SHEwry: A conformational study of a glutamine- and proline-rich cereal seed protein, C hordein. Biochem. J. 226, 557-562 (1985)

51. UllRICH, A., A. GRAY, D.V. GoEDdEL \& T.J. DULl: Nucleotide sequence of a portion of human chromosome nine containing a leukocyte interferon gene cluster. J. Mol. Biol. 156, 467-486 (1982)

52. Viotti, A., G. Cairo, A. Vitale \& E. Sala: Each zein gene class can produce polypeptides of different sizes. EMBO J. 4, 1103-1110 (1985)

53. WeIHER, H., M. KoNIG \& P. GruSs: Multiple point mutations affecting the simian virus 40 enhancer. Science 219, 626-631 (1983)

54. WILDE, C.D.: Pseudogenes. CRC Critical Reviews in Biochemistry 19, (4) 323-352 (1985)

Accepted by S.O. ANDERSEN 